\title{
Frontosphenoidal synostosis: a rare cause of unilateral anterior plagiocephaly
}

\author{
Sandrine de Ribaupierre • Alain Czorny • \\ Brigitte Pittet • Bertrand Jacques • Benedict Rilliet
}

Received: 30 March 2007 / Published online: 22 September 2007

(C) Springer-Verlag 2007

\begin{abstract}
Introduction When a child walks in the clinic with a unilateral frontal flattening, it is usually associated in our minds with unilateral coronal synostosis. While the latter might be the most common cause of anterior plagiocephaly, it is not the only one. A patent coronal suture will force us to consider other etiologies, such as deformational plagiocephaly, or synostosis of another suture. To understand the mechanisms underlying this malformation, the development and growth of the skull base must be considered.

Materials and methods There have been few reports in the literature of isolated frontosphenoidal suture fusion, and we would like to report a series of five cases, as the recognition of this entity is important for its treatment.
\end{abstract}

Presented at the Consensus Conference on Pediatric Neurosurgery, Rome, 1-2 December 2006.

S. de Ribaupierre $(\bowtie) \cdot B$. Rilliet

Department of Neurosurgery, CHUV,

Rue de Bugnon,

1011 Lausanne, Switzerland

e-mail: s_derib@hotmail.com

\section{A. Czorny}

Department of Neurosurgery, CHU,

Besançon, France

B. Pittet

Plastic and Reconstructive Surgery, HUG,

Geneva, Switzerland

B. Jacques

Maxillo-Facial Surgery, CHUV,

Lausanne, Switzerland

B. Rilliet

Department of Neurosurgery, HUG,

Geneva, Switzerland
Conclusion Frontosphenoidal synostosis must be searched in the absence of a coronal synostosis in a child with anterior unilateral plagiocephaly, and treated surgically.

Keywords Craniosynostosis · Pediatric neurosurgery · Anterior plagiocephaly

\section{Introduction}

Harmonious cranial growth is dependent on patent sutures, and any craniosynostosis might lead to an asymmetrical shape of the skull. The anterior skull base is formed of different bones, connected by sutures, fusing at different ages. The frontosphenoidal suture extends from the end of the frontoparietal suture, anteriorly and inferiorly in the temporal fossa, then continues medially across the anterior cranial base to the orbital roof $[13,14,18]$. Morphogenetically, the frontosphenoidal suture is composed of two different unities [5]. The first portion, situated medially, between the orbital part of the frontal bone and the lesser sphenoid wing is part of the anterior cranial fossa. The second portion, laterally, between the frontal bone and the great wing of the sphenoid is included in the middle cranial fossa. While the first part is a chondromembranous junction [9], formed by five layers between the ala orbitalis and the frontal bone, the second part develops between two membranous ossification centers like any other sutures [5]. It usually fuses around the age of 7 years [14].

Frontosphenoidal synostosis has been described associated with complex synostosis and with coronal synostosis but rarely as an isolated entity. A few cases of isolated frontosphenoidal synostosis have been described by Francel et al. [11], Rogers et al. [16], and Dundulis et al. [10]. 
Fig. 1 Case 1 Frontal asymmetry with left frontal flattening, ipsilateral deviation of the tip of the nose, fronto-temporal junction depression

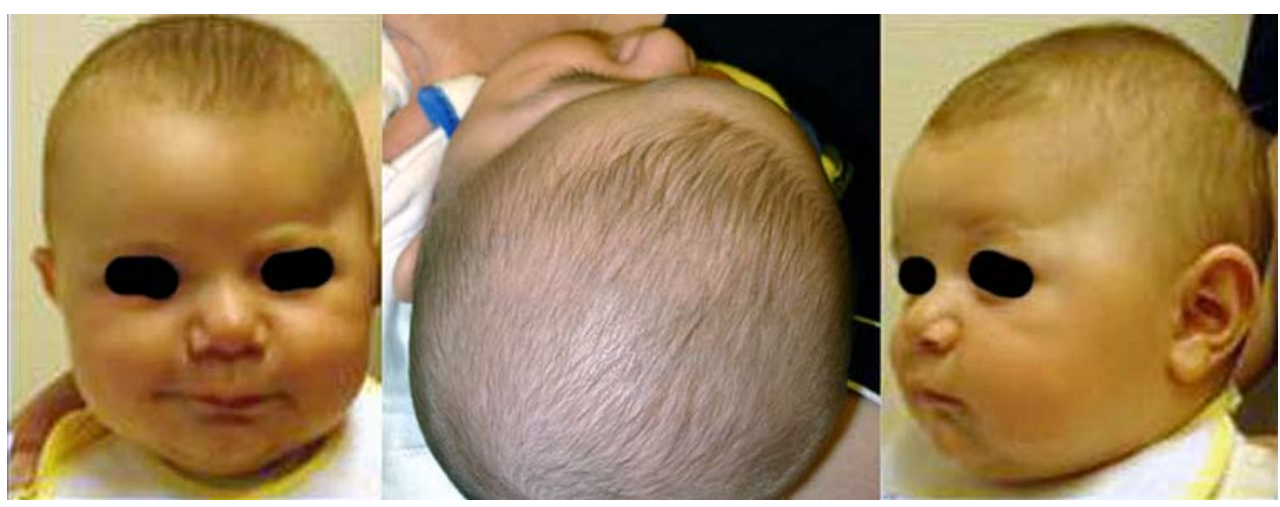

The morphology of the children affected might resemble unilateral coronal synostosis, but subtle differences might be found during the clinical status. However, a computed tomography (CT) scan is required for diagnosis.

We present in this paper five cases of isolated frontosphenoidal synostosis with emphasis on the clinical features and physiopathology.

\section{Case reports}

\section{Case 1}

A 6-month-old male infant was referred to our clinic for a left frontal flattening. The obstetrical history was unremarkable and the delivery. His parents had noted the asymmetry early after birth but were alarmed with the progressive deformation.

On clinical examination, there was a left frontal flattening, a slight deviation of the tip of the nose toward the flattening, but no harlequin's eye. A depression could be seen at the fronto-temporal junction. The cranial perimeter was normal for the age (Fig. 1). On CT scan, there were patent coronal sutures, the size of the orbit was slightly smaller on the left, and there was a thickening of the pterion, with a retrusion of the greater sphenoidal wing.
On the 3D reconstruction, there was a clear synostosis of the left frontosphenoidal suture (Fig. 2). The ethmoidal axis was deviated $10^{\circ}$ on the right. The angle between the petrosal pyramids and the midline (posterior-petrosalsagittal angle, PPSA) was $58^{\circ}$ on the left side and $50^{\circ}$ on the right side $\left(108^{\circ}\right.$ total).

The parents were informed of the cosmetic aspect of the surgery and, concerned with the progressive deformation, wished for it to be done. Bilateral fronto-orbital advancement was planned. During surgery, we could assess the synostosis of the frontosphenoidal suture on the left side. Frontal craniotomy was undertaken, followed by bilateral fronto-orbital advancement. Postoperative follow-up showed a nice cosmetic result, albeit with left smaller orbit, which progressively widened with time (Fig. 3).

\section{Case 2}

The second case was a one-year-old boy, who had a right plagiocephaly with right orbital hypoplasia, and the tip of the nose was deviated toward the flattening (Table 1).

His CT scan showed patent coronal sutures but a fused fronto-sphenoidal suture on the right (Fig. 4).

He was treated surgically with a fronto-orbital bandeau and remodeling of the frontal vault (Fig. 5). The postoperative follow-up was uneventful, with good esthetical result.

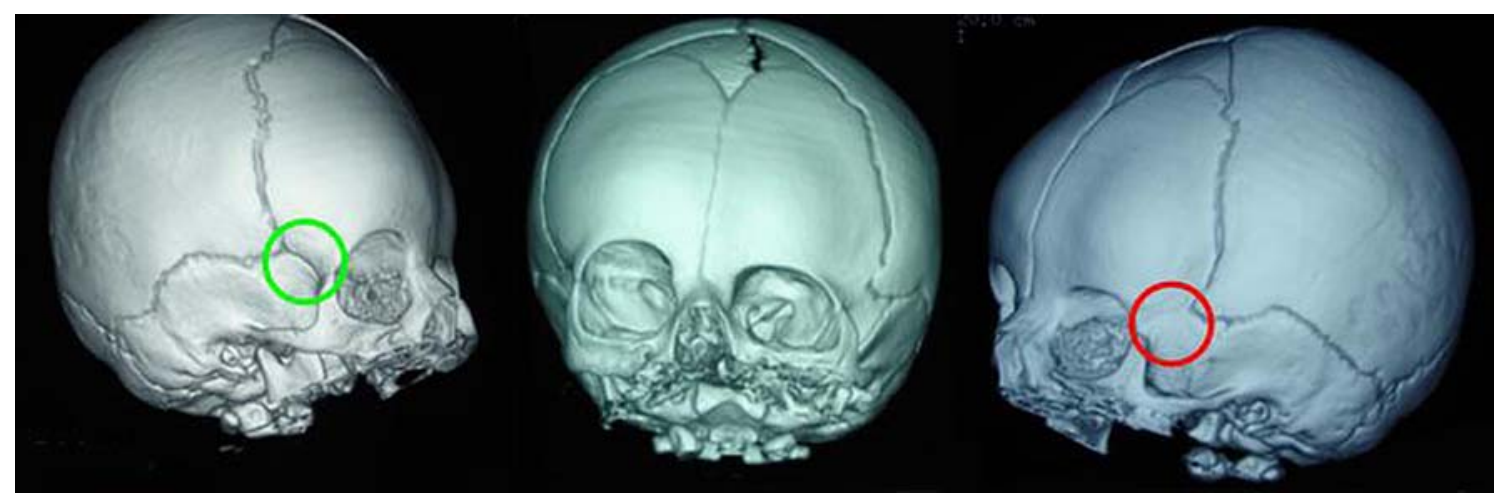

Fig. 2 Case 1 3D CT reconstruction. The green circle shows the fronto-sphenoidal suture on the healthy side, on the left side, the frontosphenoidal synostosis (absence of suture) is shown in the red circle. Notice on the face view, the smaller orbit is on the affected side 
Fig. 3 Case 1 Post-operative (4 months) result. The left orbit still looks smaller than the right one

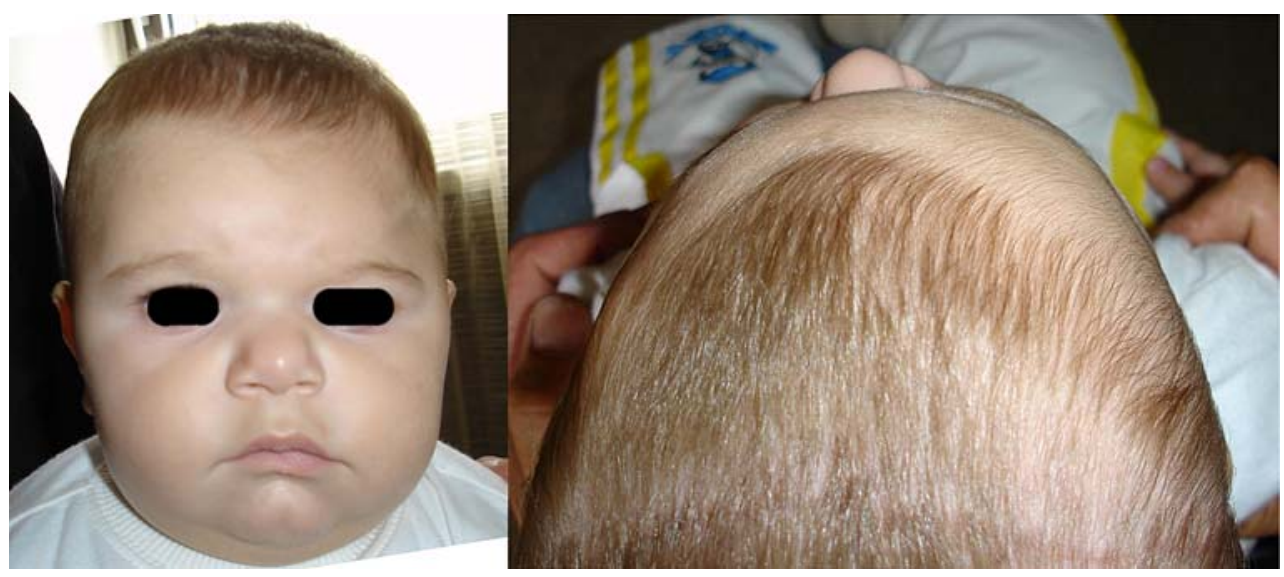

\section{Case 3}

The third case was a 6-month-old male infant who presented with a right frontal flattening, without nose deviation (Fig. 6) (Table 1). On CT scan (Fig. 7), there was a visible synostosis of the frontosphenoidal suture. He underwent bilateral orbito-frontal advancement, with good cosmetic results (Fig. 6, right image).

\section{Case 4}

A 6-year-old boy was referred to the clinic for a right frontal flattening. Clinically, he had a developmental retardation and behavioral problems. On CT, although the synostosis of the frontosphenoidal suture was harder to assess, there were patent coronal sutures (Fig. 8) (Table 1). In this case, there was an associated disappearance of the subarachnoid spaces.

The operation consisted of bilateral fronto-orbital advancement, with remodeling of the temporo-parietal bone on the right. During the operation, confirmation of frontosphenoidal synostosis was made. A nice cosmetic result was achieved.
Case 5

A boy of was seen at the age of 2 years and 3 months for a persistent recession of right forehead. This frontal asymmetry was noticed by the parents after birth and progressively got worse. The tip of the nose was slightly deviated to the right side (Fig. 9). Cranial perimeter was normal as the neurological development. CT scan without $3 \mathrm{D}$ reconstruction showed that both coronal sutures were patent (Fig. 10).

This boy underwent a bilateral fronto-orbital advancement. A fused fronto-sphenoidal was noticed during surgery. The cosmetic result was good (Fig. 11).

\section{Discussion}

Malformation and deformation can lead to unilateral frontal flattening [4]. The incidence of deformational anterior plagiocephaly has dropped since the adoption by pediatricians of a supine sleeping position for infants [1] with an increased incidence of deformational posterior plagiocephaly. Nowadays, the very frequent posterior deformational

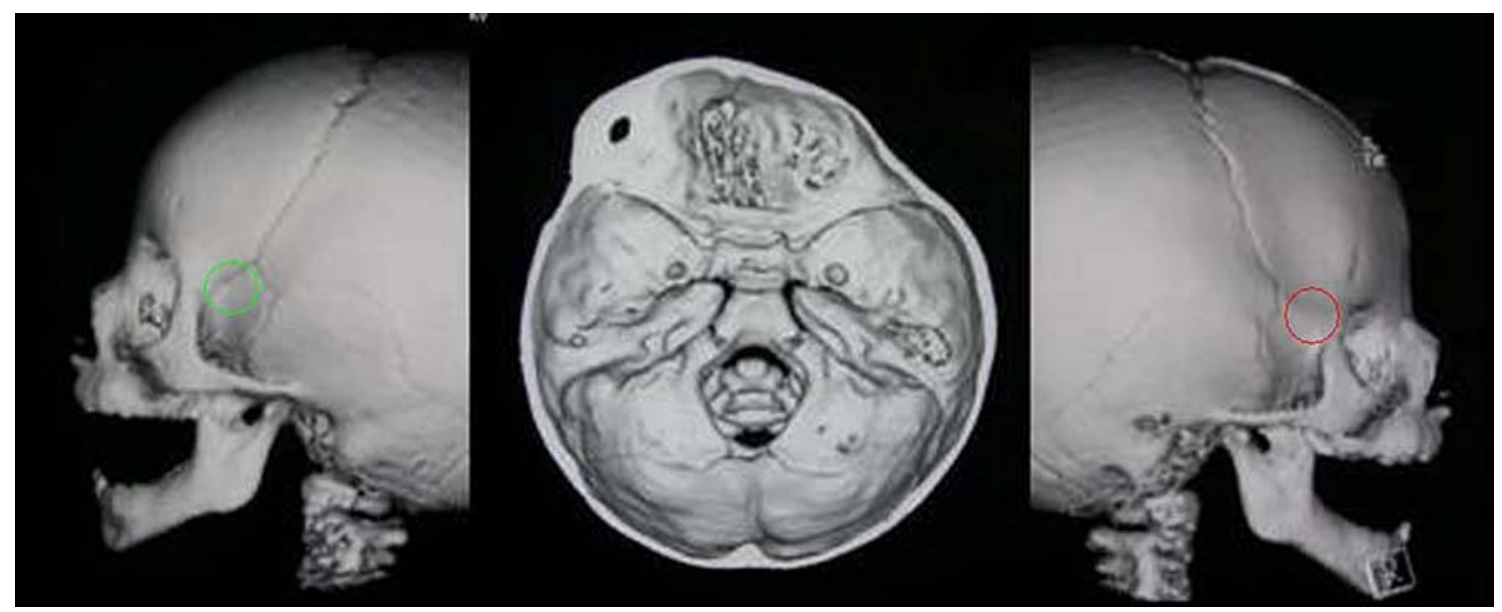

Fig. 4 Case 2 3D CT reconstruction demonstrating patent coronal sutures and the absence of the right frontosphenoidal suture. Deviation of the ethmoidal axis to the left 
Fig. 5 Case 2 Intraoperative asymmetry of the frontosphenoidal sutures shows the normal anterior fontanel and right coronal suture and the fused frontosphenoidal suture on the right side

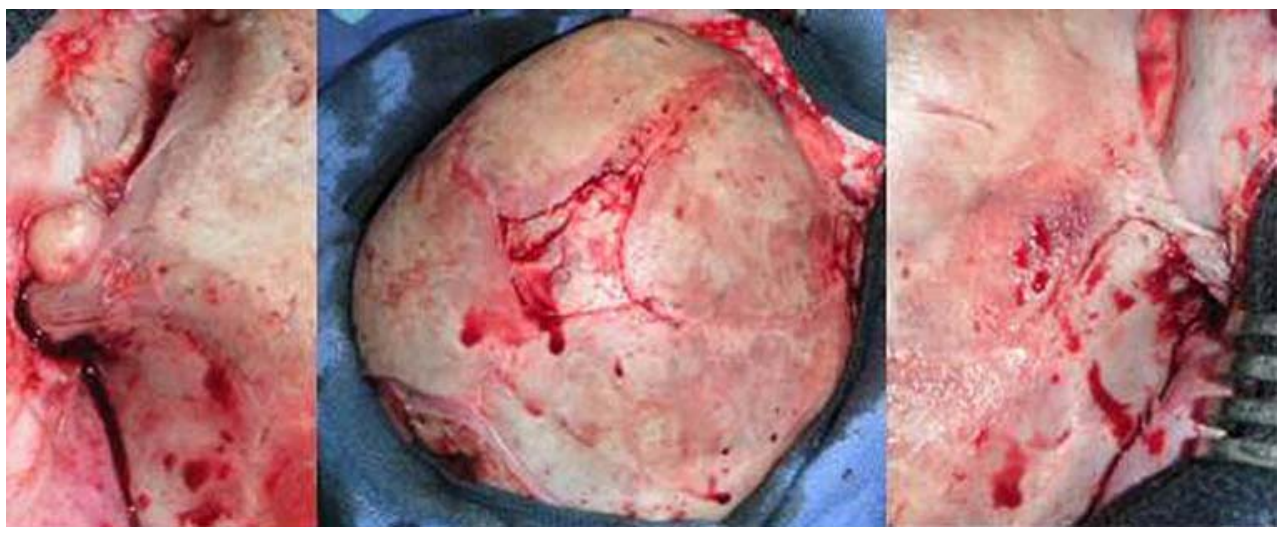

plagiocephaly is not related to the premature fusion of a suture and resolves in most cases with positional exercises or in selected severe cases with an dynamic orthosis and is not a surgical condition. Conversely, synostosis will not resolve spontaneously or with conservative treatment and will require surgery. As illustrated in these case reports, a patent coronal suture in a patient with unilateral frontal flattening might not be deformational, and the underlying cause has to be searched for.

Since Virchow described the overgrowth compensation of the adjacent prematurely fused suture, many theories have been developed to explain the remodeling of the skull $[6,12,13,15,18]$. The understanding of the cranium as two hemi-rings, as developed by Rogers, is compatible with the findings in our cases. After observations of coronal synostosis, syndromic synostosis, and three cases of frontosphenoidal synostosis, Rogers described skull growth as the result of the growth of two hemi-rings, with subsequent undergrowth of the entire hemi-ring ipsilateral to the synostosis $[16,17]$. This would result in shorter temporal, sphenoidal, and zygomatic bones of the ipsilateral side. Bertelsen [3] had already foreseen the importance of the frontosphenoidal suture as part of the suture ring formed by the coronal, the frontosphenoidal, and the sphenoeth- moidal sutures: "It is easy to imagine how a cessation of growth in this suture ring cannot be completely compensated by any other suture."

The skull can also be divided into different arches all converging on the sphenoidal bone (Fig. 12) [8]. The coronal arch, affected in our cases, begins at the bregma, divides into an anterior branch composed of the frontosphenoidal, then ethmoido-sphenoidal suture, and a posterior branch with the spheno-squamous and spheno-petrosal sutures. The sagittal arch is composed of the ethmoidofrontal synchondrosutures and the metopic and sagittal sutures. It is responsible for the lengthening of the skull. The lambdoid arch starts at lambda and the lambdoid sutures, extending to the occipito-petrosal and sphenooccipital synchondrosis.

Finally, the parieto-squamosal arch is joining the coronal and lambdoid arches and is responsible for the vertical growth of the skull.

Complex synostosis and complete coronal synostosis might involve the frontosphenoidal suture. In a study by Rogers and Mulliken [17], all children presenting with coronal synostosis older than 3 years old had a fusion of the ipsilateral frontosphenoidal suture. This "classical" plagiocephaly, in its later stage, does not only involve the
Fig. 6 Case 3 Frontal asymmetry, with right frontal flattening. Right hand side Post-operative superior view showing a symmetrical forehead
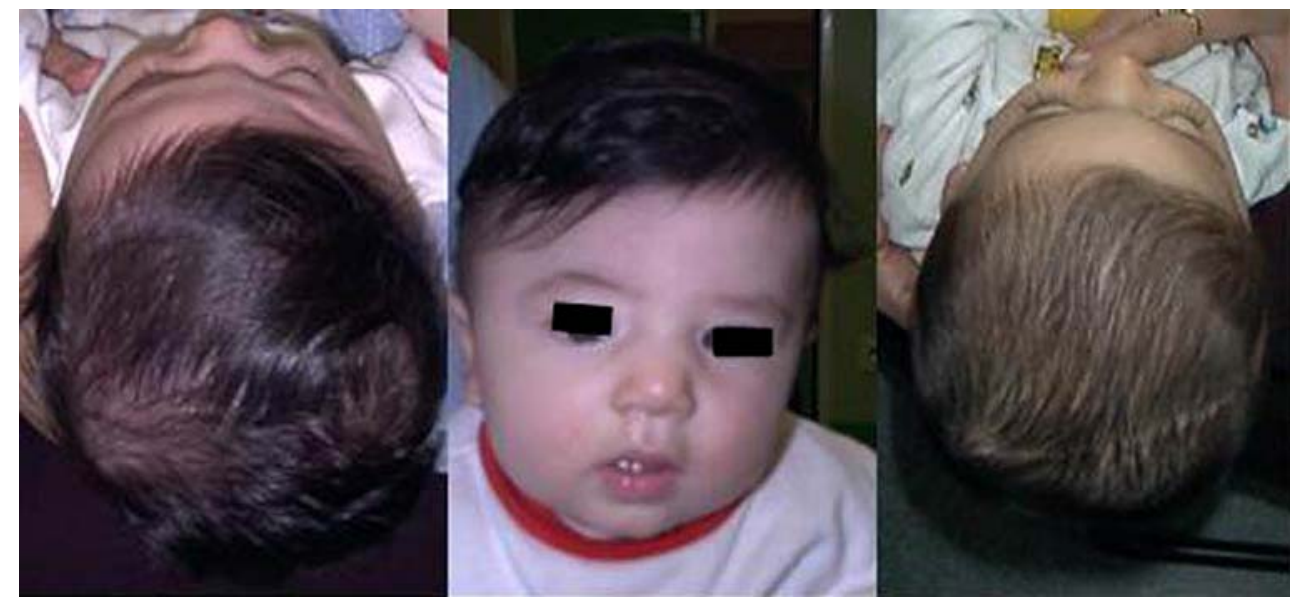


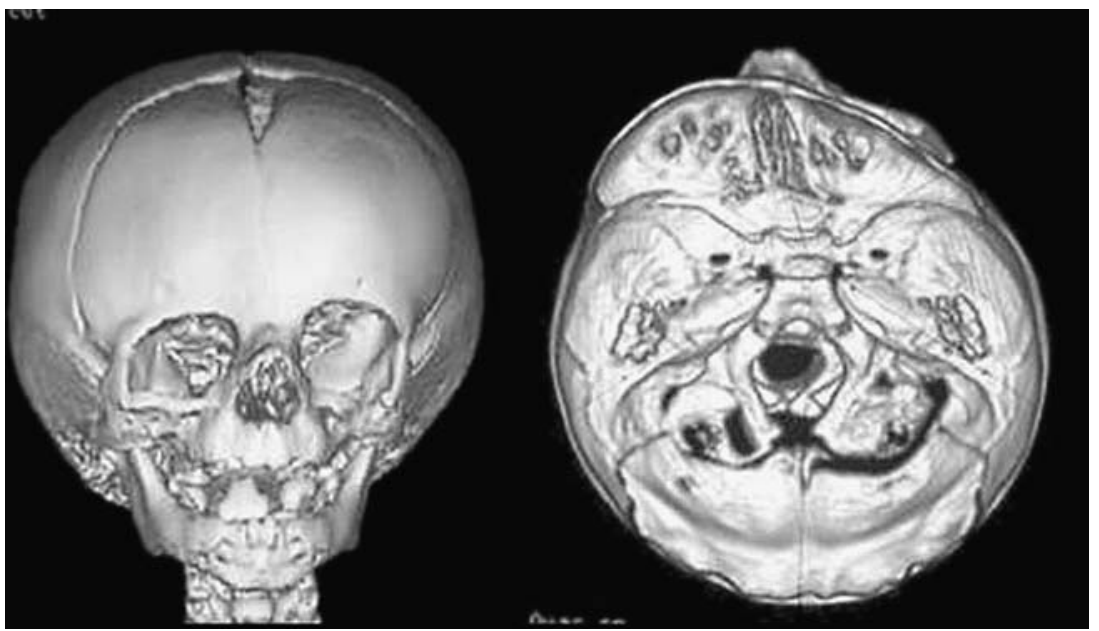

Fig. 7 Case 3 3D CT reconstruction with patent coronal sutures. Deviation of the ethmoidal axis to the left

fronto-parietal suture - "coronal suture"- - but also the frontosphenoidal, sphenoido-petrosal, and sphenoido-squamosal sutures. This supports the theory in which the middle coronal suture fuses first, followed by progression to the anterior fontanelle and to the frontosphenoidal suture [17].

Isolated frontosphenoidal synostosis, with a patent coronal suture, would have a different starting point and has been described in few cases $[10,11,16]$. Its recognition is important to assure the child a proper treatment. Isolated frontozygomatic synostosis, as a cause of an anterior plagiocephaly, has also been reported [7].

Clinically, frontosphenoidal synostosis seems to have a weaker phenotype than the coronal synostosis. As in coronal synostosis, a unilateral frontal flattening is seen; however, it might be associated with or without a controlateral nose deviation (ipsilateral deviation in coronal synostosis). The ipsilateral superior orbital rim has been described as elevated [11] or depressed [16]. The typical harlequin deformity described in coronal synostosis, with verticalization of the orbit, is usually not seen and has not been diagnosed in our series. According to Dundulis et al. [10], this deformity might be related with a compensatory growth at the patent frontosphenoidal suture in case of coronal synostosis, as the distortion is lessened when there is a complete coronal and frontosphenoidal synostosis. This may explain the absence of harlequin's eye in isolated frontosphenoidal synostosis.

These signs might be subtle, and it is difficult to note the difference clinically between coronal synostosis, deformational anterior plagiocephaly, and isolated frontosphenoidal synostosis.

In the case of frontosphenoidal synostosis, the CT scan will reveal a patent coronal suture, but enlarged pterional area, and the $3 \mathrm{D}$ reconstruction will help in enhancing the frontosphenoidal suture synostosis.

$3 \mathrm{D}$ reconstruction might also help in measuring the basal cranium's angles. A study of those angles has been made in normal subjects by Czorny [18]. The average angles

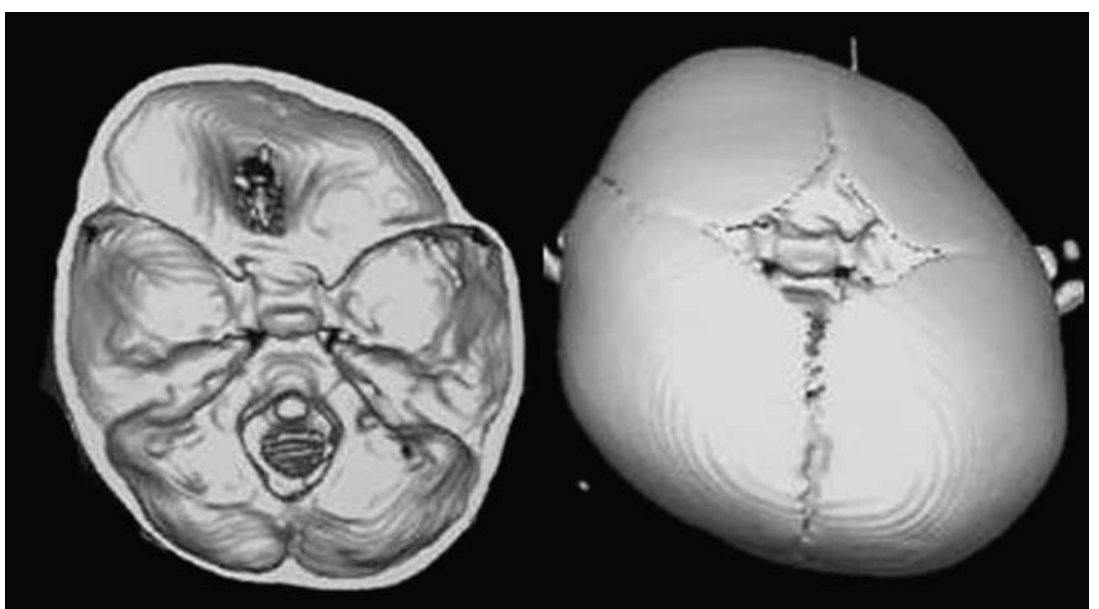

Fig. 8 Case 4 3D CT reconstruction with a right frontal flattening, with ethmoidal deviation controlateral to the flattening 


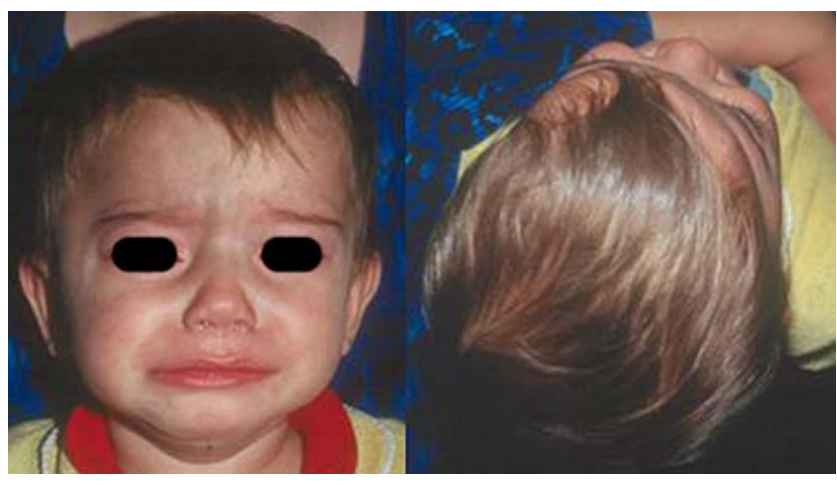

Fig. 9 Case 5 Asymmetric fore head on the right side

between the petrosal pyramids and the midline (PPSA) is $57^{\circ}$ for each side (total, $114.5^{\circ}$; range, $96-130^{\circ}$ ) and is symmetrical.

In classical plagiocephaly, this angle (PPSA) tends to be wider (average total, $118^{\circ}$ ) and asymmetrical, $51^{\circ}$ on the normal side but $64^{\circ}$ on average on the synostotic side [8].

In our series, the petrosagittal angles are also asymmetrical, with a wider angle on the synostotic side in the majority of cases (4/5), with an average of $59^{\circ}$ for the synostotic side and $55.5^{\circ}$ for the controlateral side (total, $114.5^{\circ}$ ).

While in normal subjects, there is no ethmoidal axis deviation, in coronal synostosis, there is a deviation toward the synostotic side of $18^{\circ}$ on average (range, $7-20^{\circ}$ ) [8].

A deviation of the ethmoidal axis is seen, controlateral to the fusion, between 10 and $21^{\circ}$ in our series with an average of $15^{\circ}$ (Fig. 13).

In the published cases of frontosphenoidal synostosis, the same pattern of controlateral ethmoidal angulation is seen $[11,16]$. The posterior petrosal-sagittal angle was not studied.

Diagnosis of this entity is important not only to propose the correct treatment but also to plan surgery. As in unilateral coronal synostosis, bilateral orbital advancement is recommended. Early surgery, between the ages of 6 and 9 months, as in other kinds of craniosynostosis [18], might

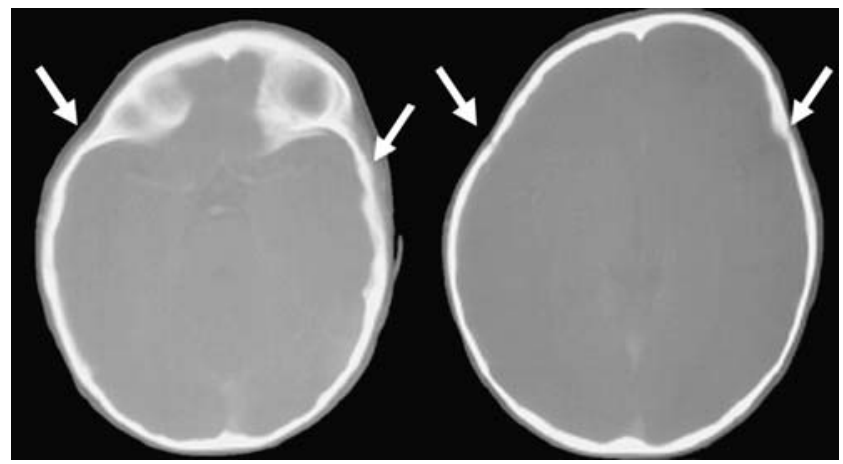

Fig. 10 Case 5 Axial CT cuts showing patent coronal suture on both sides (white arrows)

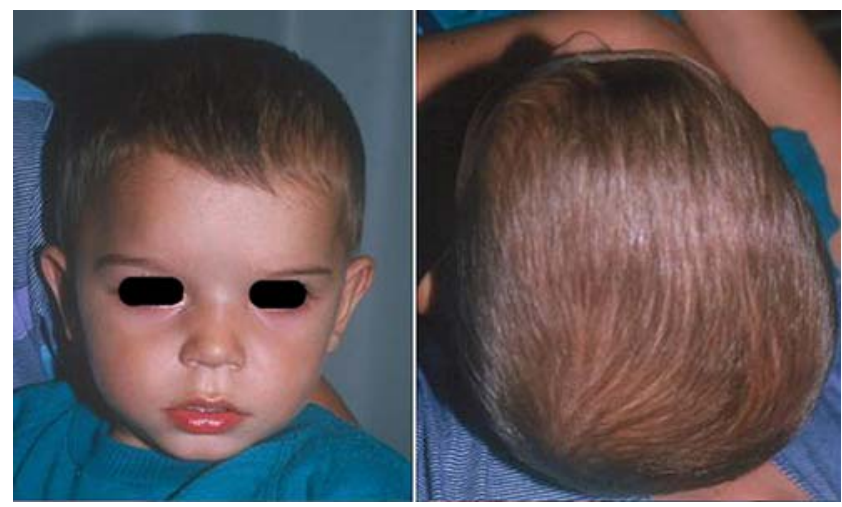

Fig. 11 Case 5 Postoperative view after 1 year, symmetrical face and forehead

need over-correction on the affected side to achieve a good cosmetic outcome and allowing a good basal expansion of the skull. Of particular importance is the correction of the smaller orbit on the side of the fronto-sphnenoidal suture. In typical coronal synostosis, harlequin's eye can be reduced if several cuts are done in the roof and lateral wall

Table 1 Summary of cases, with age of the patient, side of the synostoses, and angles measured

\begin{tabular}{llll}
\hline $\begin{array}{l}\text { Case } \\
\text { number }\end{array}$ & Age, sex & Side & Angles \\
\hline 1 & 6 months, male & Left & $\begin{array}{c}\text { Ethmoidal: } 10^{\circ} \mathrm{R} \\
\text { PPSA: } 58^{\circ} \mathrm{L}, 50^{\circ} \mathrm{R}\left(108^{\circ}\right)\end{array}$ \\
2 & 1 year, male & Right & $\begin{array}{c}\text { Ethmoidal: } 12^{\circ} \mathrm{L} \\
\text { PPSA: } 60.5^{\circ} \mathrm{R}, 62^{\circ} \mathrm{L}\left(122.5^{\circ}\right)\end{array}$ \\
3 & 6 months, male & Right & $\begin{array}{c}\text { Ethmoidal: } 19^{\circ} \mathrm{L} \\
\text { PPSA: } 57^{\circ} \mathrm{R}, 54^{\circ} \mathrm{L}\left(111^{\circ}\right)\end{array}$ \\
4 & 6 years, male & Right & $\begin{array}{c}\text { Ethmoidal: } 11.5^{\circ} \mathrm{L} \\
\text { PPSA: } 65^{\circ} \mathrm{R}, 58^{\circ} \mathrm{L}\left(123^{\circ}\right)\end{array}$ \\
5 & 2 years, male & Right & $\begin{array}{c}\text { Ethmoidal: } 21^{\circ} \mathrm{L} \\
\text { PPSA: } 55^{\circ} \mathrm{R}, 53^{\circ} \mathrm{L}\left(108^{\circ}\right)\end{array}$ \\
& & & PPS \\
\end{tabular}
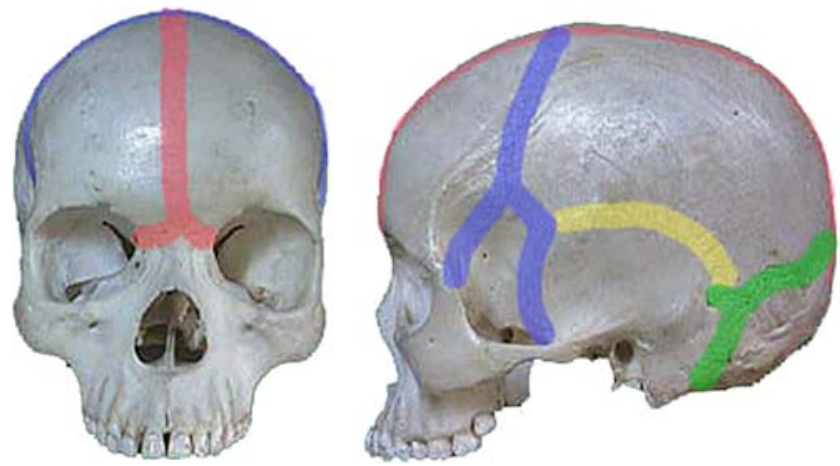

Fig. 12 The different arches drawn on the skull: red the sagittal arch, blue the anterior, and posterior branches of the coronal arch, yellow the parieto-squamosal arch, green the lamboid arch 


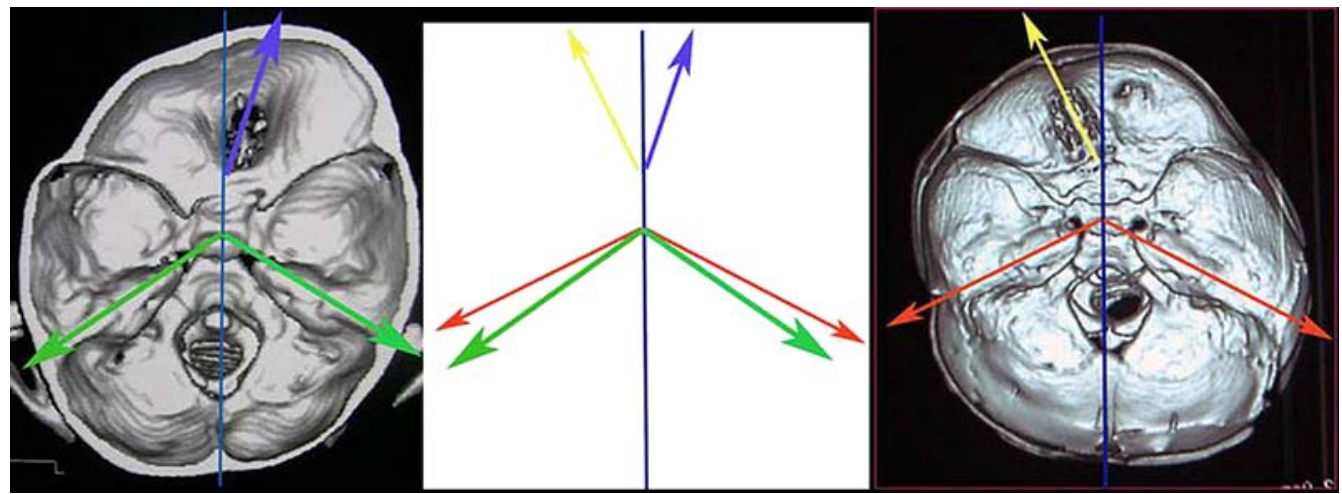

Fig. 13 Left Left frontosphenoidal synostosis, with an ethmoidal axis deviated on the opposite side. Center The different axis demonstrating the opposite directions of the ethmoidal axis for a left flattening (yellow typical plagiocephaly, blue frontosphenoidal synostosis). The
PPSA is wider in the case of typical plagiocephaly (red typical plagiocephaly, green frontosphenoidal synostosis). Right Typical plagiocephaly with a left coronal synostosis. The ethmoidal axis is deviated toward the flattening of the orbit and green-stick downward fractures [2]. We suggest that in case of fronto-sphenoidal synostosis with an ipsilateral smaller orbit, the green-stick fractures should be made in a reverse fashion (upward and lateral) to enlarge the smaller orbit.

Anterior synostotic plagiocephaly has strong female predominance. On the contrary, all cases of frontosphenoidal synostosis gathered from the literature and of our own case material are described in boys. It is also interesting to point out from the ethnological aspect that all the cases reported in the present paper originate from Turkey or are of Balkan origin. Origins of children in the other cases reported in the literature are unknown, and our series is too small to evoke a genetic aspect. But it might, however, be more than just a coincidence.

\section{Conclusion}

Isolated frontosphenoidal synostosis remains a rare pathology but has to be recognized to treat the children affected correctly. The clinical features do vary slightly from a deformational plagiocephaly or from a coronal synostosis; however, it might be subtle enough not to be diagnosed without a CT scan.

A thin bony window over the pterion area and 3D reconstruction might be helpful in the diagnosis. In the absence of clear synostosis of the suture, controlateral deviation of the ethmoidal axis might be a hint toward the diagnosis.

All the cases illustrated in this paper benefited from orbito-frontal bilateral advancement, as would have been done for "classical" anterior plagiocephaly. We believed that this method leads to good cosmetic results in the majority of cases.

Even if there is a trend toward a reduction of investigations in children presenting with plagiocephaly, we believe it is important to obtain a CT scan (with 3D reconstruction) of the frontal plagiocephaly because a differential diagnosis of unilateral coronal synostosis exists.

\section{References}

1. American Academy of Pediatrics AAP Task Force (1992) On infant positioning and SIDS: positioning and SIDS. Pediatrics 89 (6 Pt 1):1120-1126

2. Bartlett SP, Whitaker LA, Marchac D (1990) The operative treatment of isolated craniofacial dysostosis (plagiocephaly): a comparison of the unilateral and bilateral techniques. Plast Reconstr Surg 85(5):677-683

3. Bertelsen $T$ (1958) The premature synostosis of the cranial sutures. Acta Ophtalmol 36(Suppl 51):1-176

4. Bruneteau RJ, Mulliken JB (1992) Frontal plagiocephaly: synostotic, compensational, or deformational. Plast Reconstr Surg 89 (1):21-31

5. Captier G, Leboucq N, Bigorre M, Canovas F, Bonnel F, Bonnafe A et al (2003) Plagiocephaly: morphometry of skull base asymmetry. Surg Radiol Anat 25(3-4):226-233

6. Cohen MM Jr (1991) Etiopathogenesis of craniosynostosis. Neurosurg Clin N Am 2(3):507-513

7. Currarino G (1985) Premature closure of the frontozygomatic suture: unusual frontoorbital dysplasia mimicking unilateral coronal synostosis. AJNR Am J Neuroradiol 6(4):643-646

8. Czorny A (2006) Movement of bone at the base and dysmorphogenesis of the skull. Neurochirurgie 52(2-3 Pt 2):160-183

9. Dambrain R (1993) Microanatomie du squelette céphalique. In: Stricker M, Raphael B (eds) Croissance cranio-faciale normale et pathologique. Morphos, Reims, pp 191-233

10. Dundulis JA, Becker DB, Govier DP, Marsh JL, Kane AA (2004) Coronal ring involvement in patients treated for unilateral coronal craniosynostosis. Plast Reconstr Surg 114(7):1695-1703

11. Francel PC, Park TS, Marsh JL, Kaufman BA (1995) Frontal plagiocephaly secondary to synostosis of the frontosphenoidal suture. Case report. J Neurosurg 83(4):733-736

12. Friede H, Lilja J, Andersson H, Johanson B (1983) Growth of the anterior cranial base after craniotomy in infants with premature synostosis of the coronal suture. Scand J Plast Reconstr Surg 17 (2):99-108 
13. Goodrich JT (2005) Skull base growth in craniosynostosis. Childs Nerv Syst 21(10):871-879

14. Hoyte DA (1991) The cranial base in normal and abnormal skull growth. Neurosurg Clin N Am 2(3):515-537

15. Richtsmeier JT, Grausz HM, Morris GR, Marsh JL, Vannier MW (1991) Growth of the cranial base in craniosynostosis. Cleft Palate Craniofac J 28(1):55-67
16. Rogers GF, Proctor MR, Mulliken JB (2002) Unilateral fusion of the frontosphenoidal suture: a rare cause of synostotic frontal plagiocephaly. Plast Reconstr Surg 110(4):1011-1021

17. Rogers GF, Mulliken JB (2005) Involvement of the basilar coronal ring in unilateral coronal synostosis. Plast Reconstr Surg 115(7):1887-1893

18. Sgouros S (2005) Skull vault growth in craniosynostosis. Childs Nerv Syst 21(10):861-870 